\title{
Assessing the effectiveness of IPTEACES e- learning framework in higher education: Fundação Dom Cabral - a Brazilian perspective
}

\author{
Nuno Pena, ADVANCE Research Center ISEG - Lisboa School of Economics and \\ Management, Lisbon, Portugal, npena@iseg.ulisboa.pt \\ Paula Simões, Fundação Dom Cabral, Nova Lima/MG, Brazil, paula@fdc.org.br \\ Lília Mascarenhas, Fundação Dom Cabral, Nova Lima/MG, Brazil, \\ lilia.mascarenhas@fdc.org.br
}

Flávia Alvim, Fundação Dom Cabral, Nova Lima/MG, Brazil, flavia.alvim@fdc.org.br

\begin{abstract}
E-learning's quality has become an issue of increasing importance in both researchers' and practitioners' communities. Involvement, Preparation, Transmission, Exemplification, Application, Connection, Evaluation and Simulation (IPTEACES) is an e-learning framework, primarily developed through a pedagogical benchmarking. It addresses an assorted social-demography and geographically dispersed variety of attendees. Fundacão Dom Cabral (FDC) is a prestigious Brazilian business school with international standards and procedures. This study reports the application of the IPTEACES e-learning framework in higher education in Fundação Dom Cabral's Master of Business Administration (MBA) program. An experiment has been put into place to measure 'quality' through the assessment of the effectiveness of the e-learning program using IPTEACES e-learning framework, and more specifically, (i) to evaluate how the IPTEACES e-learning framework can promote students' learning; (ii) to assess its effectiveness and determine specific quality improvement measures'; and (iii) to evaluate how the IPTEACES e-learning framework enhances organizational learning approach for enhanced knowledge sharing. Qualitative and quantitative techniques were utilized to collect the data to address the research questions proposed in this study. Results showed that the application of the IPTEACES e-Learning framework to this new course has reached high effectiveness.
\end{abstract}

Keywords: E-learning, quality improvement, effectiveness assessment of knowledge sharing programs, IPTEACES e-learning framework, instructional design, program learning effectiveness.

\section{Introduction}

\section{E-learning Quality}

The rapid growth of online academic programs in higher education has prompted institutions to develop processes and implement strategies to ensure the quality of their online offerings (Britto, Ford, \& Wise, 2014). In the field of learning, education, training, and knowledge sharing, specifically when facilitated via e-learning, 'quality' 
has become an issue of increasing importance in both researchers' and practitioners' communities (Ehlers, Camilleri, \& Pawlowski, 2014; Pena, 2016). However, there is no common understanding about the terminology or the methodology of quality, because quality can be seen from a variety of perspectives and dimensions. 'E-learning quality' is not an absolute and fixed category, but rather depends on the situation in which it is employed (Ehlers \& Hilera, 2012). "There is no simple definition of quality in elearning and any definition we might wish to consider runs the risk of constraining people vision of what quality means and its significance in their particular context" (Dondi, Moretti, \& Nascimbeni, 2006, p. 32). A widely used definition by Juran (1992), which was adopted from Ball (1985) is "fitness for purpose" (p. 92). Moreover, Grönroos (2007) claimed that what counts is quality as it is perceived by customers. Additionally, Ehlers and Hilera (2012) defended that, of all the dimensions and aspects of e-learning quality, the perspective of the learner is probably the most important.

The International Organization for Standardization (ISO) (2000), which is responsible for international management standards, defined 'quality' as a characteristic that a product or service must have. For example, products must be reliable, usable, and repairable; similarly, service should be courteous, efficient, and effective. Thus, these are some of the characteristics that a good quality product/service must have. Hence, quality is a desirable characteristic. However, not all qualities are equal. Some are more important than others. The most important qualities are the ones that customers want. Providing quality products and services is all about meeting customer requirements. It's all about fulfilling the needs and expectations of customers. So, a quality product or service is one that meets the needs and expectations of customers. Although this definition is rather generic, it will serve us as an orientation.

This study reports the application and use of an instructional design framework: Involvement, Preparation, Transmission, Exemplification, Application, Connection, Evaluation and Simulation (IPTEACES) e-learning framework in a higher education institution in Brazil. This study sought to evaluate if the service (e-learning modules) met the needs and expectations of their customers (students - as the key stakeholder), if the 'customers' (learners) value the characteristics as highly important and are highly satisfied by those same characteristics. In other words, this study aimed to investigate if IPTEACES e-learning framework can be effective in the context of Higher Education and particularly in different geographies by measuring quality through the assessment of the effectiveness of the e-learning program (Levy, 2006). This study is part of the three higher education experimentations on the application of IPTEACES e-learning framework in three business schools (namely, in Portugal, Australia, \& Brazil). This study reports on the Brazilian experience with the application of the IPTEACES framework in higher education, more specifically in Fundação Dom Cabral (FDC)'s Master of Business Administration (MBA) program.

\section{Fundação Dom Cabral (FDC) and the Executive MBA}

FDC is a prestigious Brazilian business school with international standards and procedures that focus upon the development of the analytical decision-making as well as leadership skills of executives, entrepreneurs, and public sector managers. According to the corporate reputation ranking developed by Merco consultancy, FDC is the 
executive business education school with the best reputation in Brazil and it remains as the first business school in Latin America.

FDC's Executive MBA (EMBA) is a general management training program that promotes transformational leaders, while allowing personal and organizational development. With a duration of 18 months, the program has a blended learning format, with six face-to-face modules, with intermissions of approximately three months, alternated by e-learning modules that prepare the student to the next face-to-face classes. Recently, the EMBA structure was revised and the FDC's Technical Coordination realized there was a need to add additional curriculum on Basic Finance. The Basic Finance course was created primarily as an optional course for students who are not familiar with Finance, but became a mandatory course in recent years. Its objective was to get students ready for the e-learning activities that precede the core course on Finance, which is delivered in the third face-to-face module of the EMBA. Given the nature of the Basic Finance course, the FDC team believed this goal could also be fulfilled with e-learning content, although there was a need to overcome possible resistance from students, professors in charge of the courses, and even FDC coworkers. The use of IPTEACES e-learning framework helped FDC to make all necessary alignments with everyone involved with the project.

\section{Background}

\section{IPTEACES e-Learning Framework - Brief Description}

IPTEACES is an e-learning quality assessment framework (Pena \& Isaias, 2010, 2013). This e-learning framework was primarily developed through a pedagogical benchmarking, mainly Gagne, Briggs, and Wager (1992)'s Nine Events of Instruction, Merrill (2002; 2007)'s Principles of Learning, Keller (2008; 2010)'s Attention, Relevance, Confidence, Satisfaction (ARCS)'s model, as well as Merriënboer and Kirschner (2007) 10 Steps to Complex Learning; and by investigating award winning ecourses, e.g., Brandon Hall Group (2012)'s Excellence in Learning Awards as well as Bersin and Associates (2012)'s report. IPTEACES framework addresses an assorted social-demography and geographically dispersed variety of attendees (Pena \& Isaias, 2011, 2013). It was originally conceived and designed as an instructional design framework for online corporate learning that could enable an integrated implementation of an appropriate learning strategy for different learners, considering different learning preferences and other specific differences (i.e. ages, gender, educational background, previous knowledge in the area, literacy, computer proficiency, organizational culture, motivations, as well as values \& experience/inexperience in e-learning). Figure 1 details the different phases of the framework. The following is a description of each of IPTEACES learning phases:

Involvement: This strategy aims to immerse the student in the context of a real situation, where $\mathrm{s} /$ he is confronted with a problem (Merrill, 2002; 2007). From a pedagogical perspective, it seeks to engage the student (Gagne et al. (1992)'s first event; Keller (2008)'s first principle of ARCS). 
- Preparation: This strategy is divided into two complementary stages: Presentation of "Program and Objectives" as well as "Contextualization and Activation":

a. Program and Objectives - Presentation of the program, objectives and what is expected of the student (Gagne et al. (1992)'s second event; Keller (2008)'s second principle).

b. Contextualization and Activation - this strategy seeks to make an introduction, a contextualization or a reminder of the subject so the student can activate prior existing knowledge (Gagne et al. (1992)'s third event; Merrill (2002; 2007)'s Activation principle).

- Transmission: This phase is divided into three complementary steps: Acquisition (learning content), Systematization, and Formative Assessment.

a. Acquisition - the central strategy for presenting the learning content of the course. This strategy (Gagne et al. (1992)'s fourth event) is where the new content is actually presented to the learner.

b. Systematization - after presenting a part of the new material, it is advisable to carry out systematization.

c. Formative Assessment - it is also desirable, at the end, to create a graphical representation of the relationship between the concepts and ideas (new learning material) through the use, for instance, of "concept maps" or "dynamic diagrams."

- Exemplification and Demonstration: This phase is mainly based on Merrill (2002; 2007)'s "demonstration principle" and is divided into three complementary sub-strategies: Real Case, Step-by-Step Demo, and Ask the Expert.

a. Real Case - an exemplification based on real cases and real situations and presents learners with authentic real-life situations, while illustrating the relevance of the content and demonstrating the concepts learned.

b. Step-by-Step Demo - a type of guided exemplification (Gagne et al. (1992)'s fifth event) that decomposes a problem into phases and components, while demands a detailed analysis of a commentary on the parts that constitute a complex situation or problem.

c. Ask the Expert - a phase that presents the student with a more complex situation, a structured example that may require the student to ask advice from an expert on how the problem could be resolved.

- Application and Transfer: This phase is an effort to maximize the transfer of knowledge by requiring students to flexibly apply what has been learned in new or unfamiliar situations (Gagne et al. (1992)'s fifth \& sixth event; Keller (2008)'s third principle, \& Merrill (2002; 2007)'s application principle).

- Connection: This phase focuses on asynchronous mentoring, collaboration, and tools.

a. Asynchronous Mentoring - an integrated e-mail functionality was developed in the course to enable students to tutor communication.

b. Collaboration - two kinds of discussion forums are available: Supervised discussion forums and peer discussion forums. 
c. Tools - this feature gives the student access to a glossary of terms, job aids, documentation, worksheets, etc.

- Evaluation: Self-Assessment and Summative evaluation: At the end of each learning module, the system suggests that the student submit a self-assessment. The intention is to determine whether the student, in his/her opinion, has achieved the learning objectives. Upon completing the modules, students are required to undertake a final assessment. This test, a summative evaluation, is intended to assess objectively whether the student has achieved the specific objectives of each of the learning modules. A detailed feedback follows the results of the summative assessment. This strategy relates directly to Gagne et al. (1992)'s eighth event, and to Keller (2008)'s fourth principle.

- Simulation: An exam was devised similar to the one that the candidates need to pass in the face-to-face examination after successfully completing all the elearning modules. This strategy considers Gagne et al. (1992)'s ninth event and Merrill (2002; 2007)'s Integration Principle in particular.

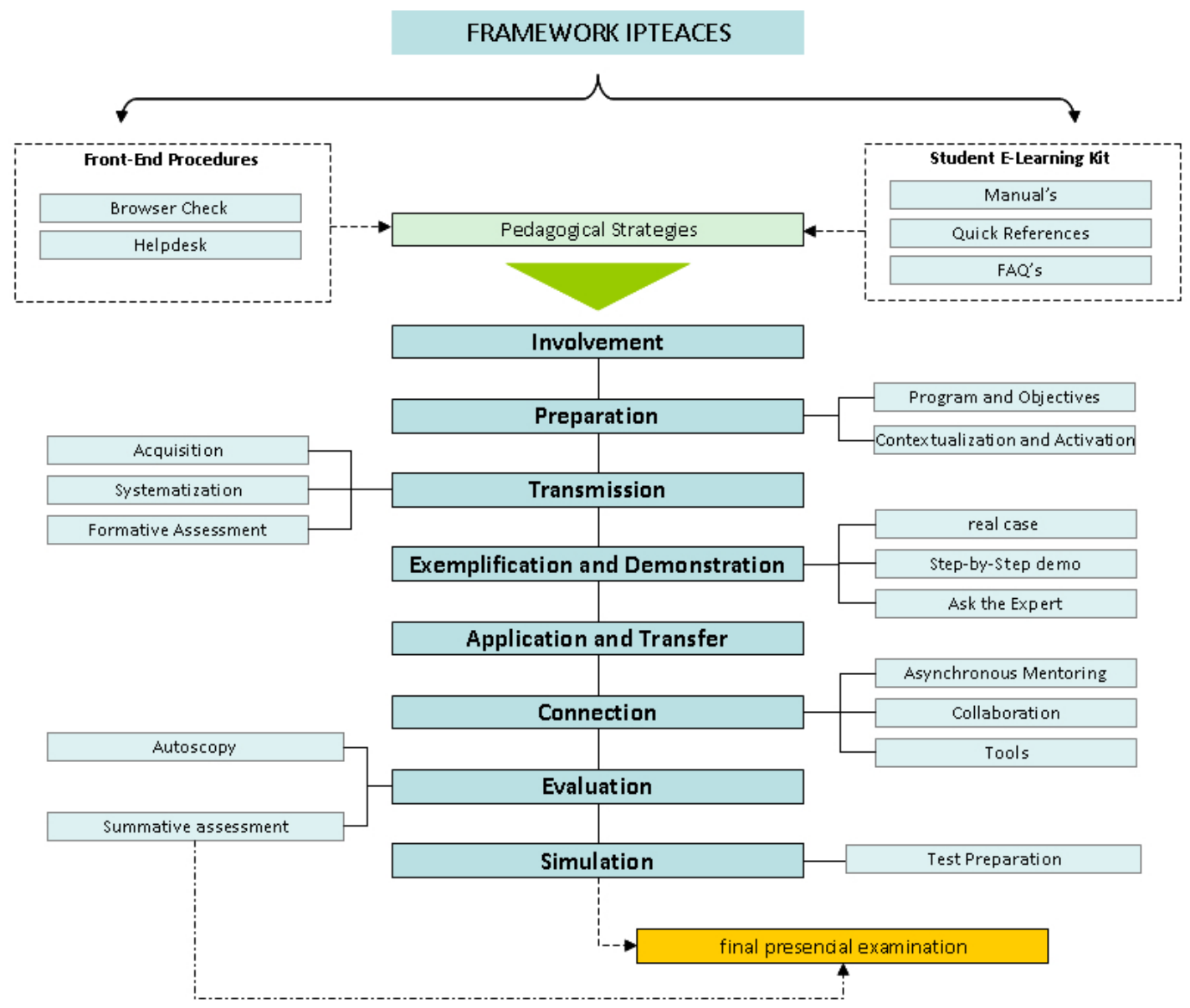

Figure 1. The IPTEACES e-learning framework adapted from Pena and Isaias (2010; 2013). 


\section{Research Questions and Methodology}

As stated previously, this study aimed to investigate if IPTEACES e-learning framework can be pedagogically effective one in the context of higher education and particularly in different geographies. It is part of the three higher education experiments of the application of IPTEACES e-learning framework in leading business schools, namely, Portugal (Pena, Gonçalves, \& Lopes, 2015), Australia (Tomayess, Pena, \& Isaias, in Press) and Brazil. This study reports the Brazilian trail of the application of the IPTEACES e-learning framework in higher education, more specifically in FDC's MBAprogram.

IPTEACES e-learning framework was applied in an FDC EMBA discipline - Basic Finance course. This study will examine the following research questions:

RQ1: How IPTEACES e-learning framework can promote students' learning?

RQ2: How to assess its effectiveness and determine specific quality improvement measures?

RQ3: How IPTEACES e-learning framework enhances organizational learning approach/products?

Qualitative and quantitative techniques were utilized to collect the data to address these research questions through the application of an online survey originally conceive by Levy (2006) as well as the gathering of students' reaction and feedback after using the new learning module (i.e. the Basic Finance course).
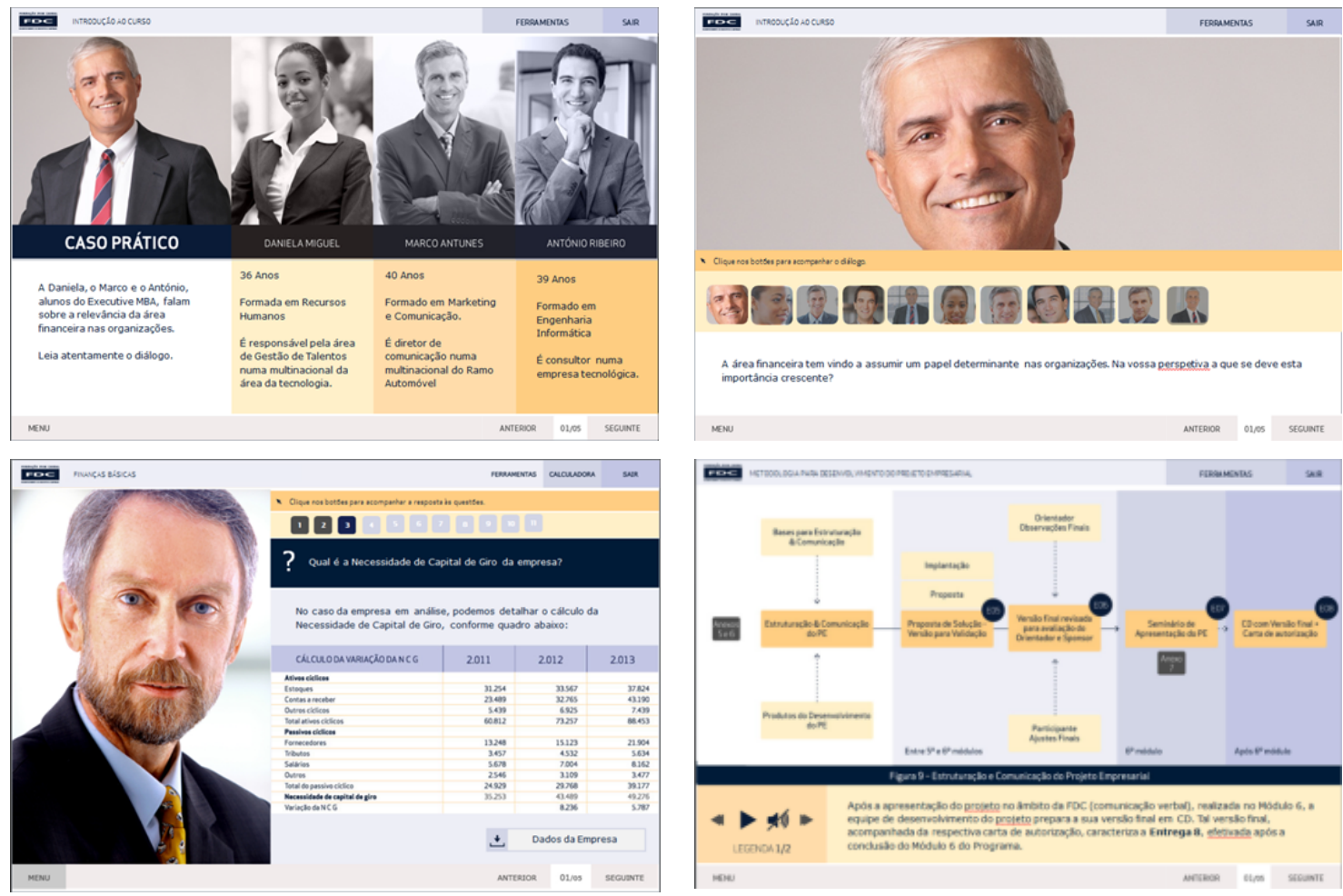

Figure 2. Examples of Print-Screens from Basic Finance course 


\section{Measuring Quality Through the Assessment of the Effectiveness of e-Learning}

In the context of this e-learning project, we sought to evaluate if the product/service (elearning courses) met the needs and expectations of the customers (students). Levy (2006) developed an investigation by querying students concerning the characteristics of e-learning that they value and consider important during their learning experience. His study attempted to understand the relationship between the value learners attribute to e-learning systems and the satisfaction learners experience with e-learning systems. Levy (2006) stated that it is not the number of satisfied students or the level of satisfaction that suggest the system's effectiveness. Rather, it is the extent to which students are more satisfied by the system performance with what they perceive as important.

Satisfaction is defined as the perceived performance level students find at a postexperience point of time with e-learning (Doll \& Torkzadeh, 1991; Levy, 2006), whereas value is defined as an enduring core belief about the level of importance students attribute to the e-learning system (Levy, 2006). Levy (2006) as well as Levy, Murphy, and Zanakis (2009), proposed measures of learners' perceived value and learners' perceived satisfaction, for assessment of the effectiveness of an e-learning system. E-learning system is defined as the entire technological, organizational, and management system that facilitates and enables students learning via the Internet (Levy \& Murphy, 2002). E-learning systems are considered effective when learners value its characteristics as highly important and are highly satisfied by those same characteristics. Levy (2006) and Levy et al. (2009) proposed a set of characteristics that learners found important, or value, when using e-learning systems. The list of e-learning systems characteristics was built primarily from an exhaustive review of literature and subsequently through exploratory focus groups, as well as in a qualitative questionnaire. Levy (2006) developed an assessment of such characteristics using a survey instrument. This survey, based upon prior validated measures from education and Information System literature, included satisfaction and value items for each of the e-learning system's characteristic, as well as learners' overall value measure, overall satisfaction measure with e-learning system, and an overall perceived learning measure. Due to the heterogeneity nature of the e-learning system characteristics proposed, Levy (2006) grouped them according to the four dimensions proposed by Webster and Hackley (1997): technology and support, course, professor, and learner's dimensions. To determine the level of effectiveness of our e-learning project, we applied Levy (2006)'s proposed methodology. However, due to the specificity of this e-learning course (asynchronous e-learning with strong component of self-learning), our online survey was then composed by three dimensions covering a total of 21 e-learning system characteristics: Course Content dimension, Access and Navigation dimension, as well as Perceived value dimension - (See Appendix A).

\section{Value-Satisfaction Grid and Learners' Value Index of Satisfaction (LeVIS Index)}

Levy (2006) and Levy et al. (2009) proposed two benchmark tools based on the outputs of the questionnaire that can be complemented: the Value-Satisfaction Grid and LeVIS 
Index. The objective of Value-Satisfaction Grid is to provide an indication for action and improvement priorities for the e-learning system dimension and the e-learning systems characteristics. The Value-Satisfaction Grid was developed in a similar manner to the Strengths, Weaknesses, Opportunities, and Threats (SWOT) used by many marketing scholars. In the adaptation to the e-learning context, the Value-Satisfaction Grid was based on aggregated student perceived satisfaction as well as aggregated student-perceived value of e-learning system characteristics. This grid was constructed by positioning the e-learning system characteristics of each dimension, where the mean characteristics satisfaction scores are positioned on the horizontal axis and the mean characteristics value scores are positioned on the vertical axis. The dimension grid was developed for each of the three dimensions. Similarly, Value-Satisfaction Grid for the overall system was constructed. In this study, the measures scale ranges from ' 1 ' to ' 6 ', while no scores were noted below ' 3 ' in satisfaction, and below ' 3 ' in value, resulting in the use of 4.5 as the cut-off point between low and high on both axes of the grid.

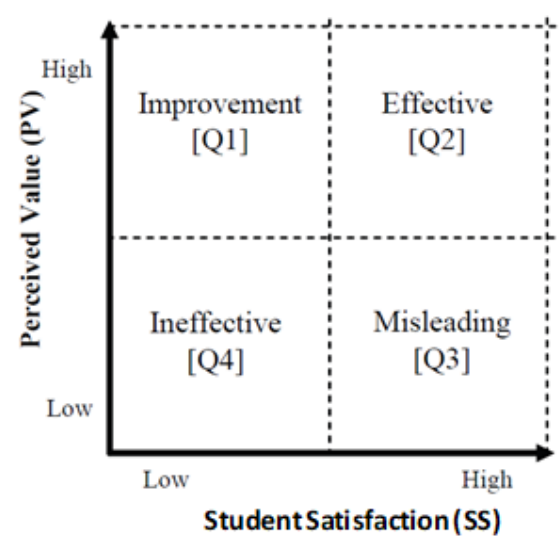

Figure 3. The Value-Satisfaction Grid (adapted from Levy (2006) \& Levy et al. (2009))

The Value-Satisfaction Grid does not provide, however, a measure of the magnitude of e-learning system effectiveness and, therefore, should be complemented with another tool. The LeVIS Index proposed by Levy (2006) provides that measure as an overall index of learners' perceived effectiveness of e-learning systems by combining elearning systems value measures and e-learning systems satisfaction measures. The LeVIS index is proposed as a benchmarking tool combining the learners' perceived value and satisfaction in order to indicate learners' perceived e-learning systems effectiveness. The Value-Satisfaction Grid suggests that it is not sufficient that only value or only satisfaction measures are high, rather the combination of both value and satisfaction. Consequently, the LeVIS Index was proposed by Levy (2006) as the multiplication of the overall satisfaction $\left(\mathrm{S}_{\mathrm{o}}\right)$ by the overall value $\left(\mathrm{V}_{\mathrm{o}}\right)$. The magnitude of LeVIS Index provides that when LeVIS Index is near 0, this indicates very low learners' perceived e-learning systems effectiveness. When LeVIS Index is near 1, this indicates very high learners' perceived e-learning systems effectiveness. This measure provides that if only one of the two measures $\left(\mathrm{S}_{\mathrm{o}}\right.$ or $\left.\mathrm{V}_{\mathrm{o}}\right)$ is high, the overall system measure (LeVIS Index) score is not high. As noted by Levy (2006), an observed limitation of LeVIS Index is due to the equal importance given for value and satisfaction. 


\section{Assessing the effectiveness of IPTEACES e-Learning Framework}

The application of the adapted version of the online survey instrument took place during approximately three months, with follow-up reminders approximately one month later of the first sending, targeting 243 students from five different classes (overall response rate of 37\%). As previously mentioned, Levy (2006) and Levy et al. (2009), proposed two benchmark tools based on the outputs of the survey that can be complemented: the Value-Satisfaction Grid and the LeVIS Index. Results from the output of the online survey are presented below in Figures 4 and 5 by using these two tools.

\section{Dimension A - Course Contents}

\section{Value-Satisfaction Grid for Dimension A}

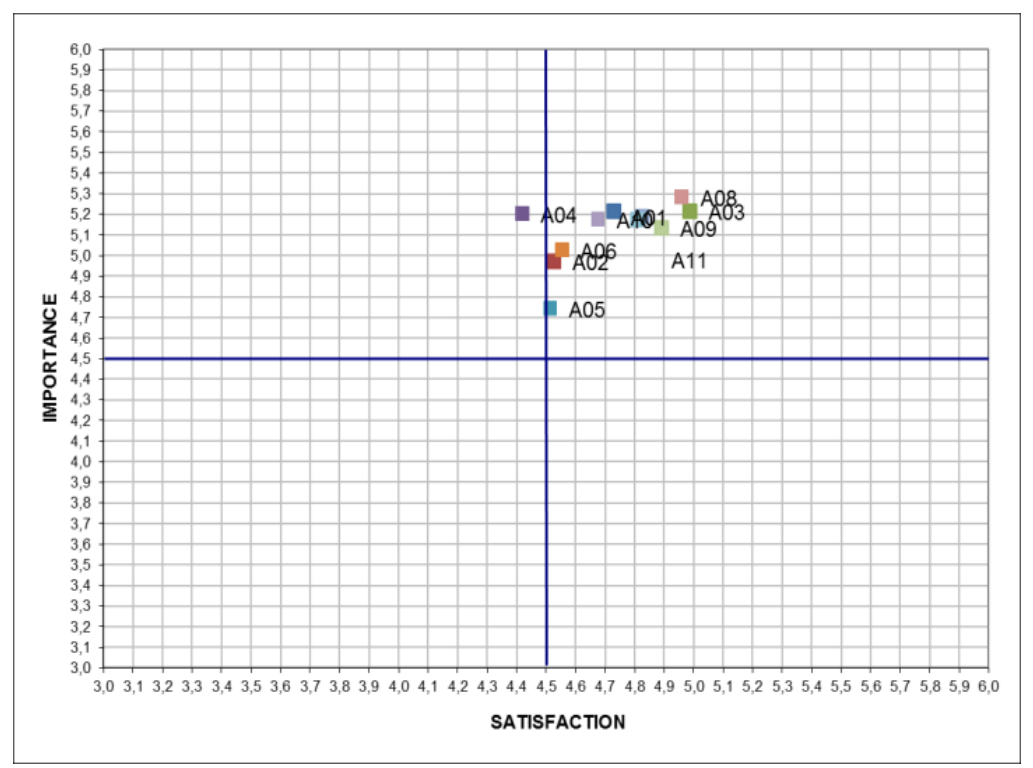

Figure 4. Value-Satisfaction Grid of Dimension A - Course Contents

Analyzing the specific data from this Value-Satisfaction Grid in Figure 4, none of the 11 e-learning system characteristics were placed in "Q4 - Ineffective quadrant" nor in the "Q3 - Misleading" quadrant. The majority (91\%) of items are concentrated in the quadrant of "high satisfaction and high value", i.e., in "Q2 - Effective quadrant". Items "A8 - Gathering information quickly", "A3 - Interesting subject matter" and "A7 Ease-of-use (with course content, navigation, interface, etc.)" are best positioned as high satisfaction and high value.

There is only one item situated in the "Q1- Improvement quadrant". Item A4 (Difficulty of subject matter) denotes high importance score from students (5.20), however, the satisfaction score is lower (4.42 - between satisfied and highly satisfied). This ValueSatisfaction Grid of Dimension A, shows that item A4 (Difficulty of subject matter) should be the priority of quality improvement measures in this Dimension. On the other hand, items A5 (Access to other contents/resources (content of courses, organization of assignments, etc. across all course modules)) and A2 (Amount of material in courses), although being placed on Q2 - Effective Quadrant, are very near of the "border" of "Q1 
- Improvement" quadrant", scoring respectively 4.51 and 4.52 in terms of satisfaction, but far from having the same the importance as A4 - particularly item A5.

\section{Learners' Value Index of Satisfaction (LeVIS Index) for Dimension A}

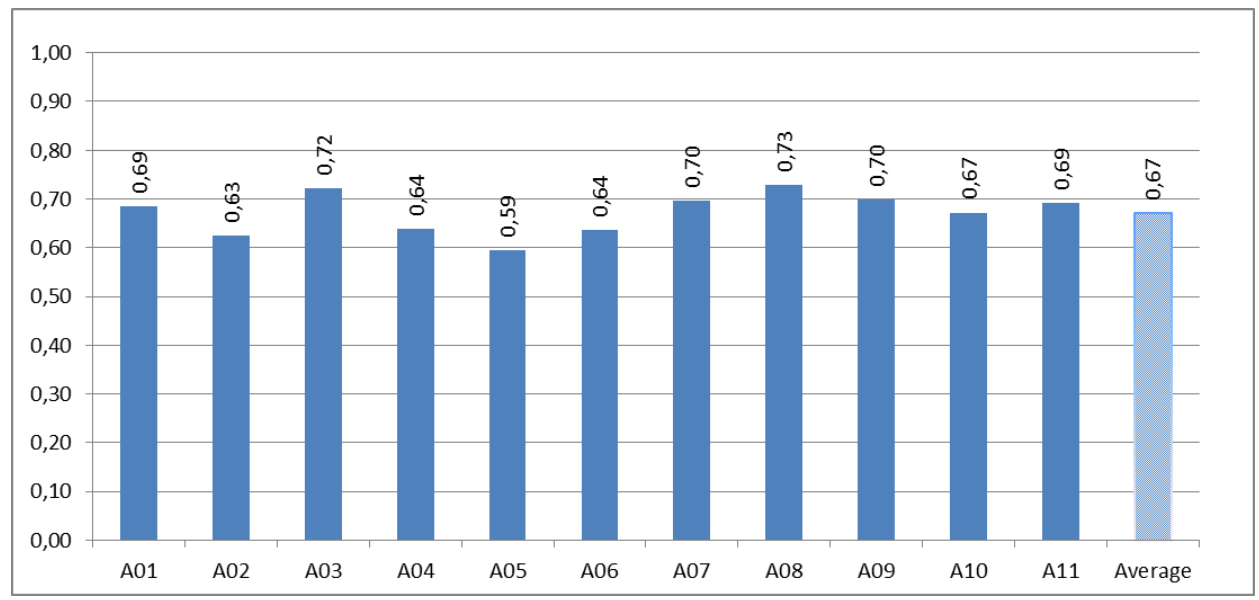

Figure 5. Learners' Value Index of Satisfaction (LeVIS Index) Dimension A - Course Contents

Given the results of LeVIS Index of "Dimension A - Content" in Figure 5, the global score reveals "good effectiveness" $(>0.56 \&<0.75)$ having a LeVIS Index score average of 0.67. More specifically, and according to Figure 5, it is possible to conclude that the highest scores belong to items "A8 - Gathering information quickly", (0.73), "A3 - Interesting subject matter" (0.72). On the other hand, characteristics A5 (availability of other content (syllabus, objectives, assignments, \& schedule)) (0.59) and A2 (amount of material in courses) (0.63), are the ones who reveal the lowest scores, however, still showing "good effectiveness" $(>0.56 \&<0.75)$.

\section{Dimension B - Access and Navigation}

\section{Value-Satisfaction Grid for Dimension B}

The Value-Satisfaction Grid for Dimension B (Figure 6) illustrates that all six elearning system characteristics were placed in the quadrant of "high satisfaction" and" high value", i.e., in "Q2 - Effective quadrant". These evaluations denote that student's value and are very satisfied with all items concerning "Access and Navigation", and with system characteristics as "availability of course content", with "asynchronous characteristics of anytime/anywhere" and with the "possibility of reviewing course materials at their convenience". The highest Importance and Satisfaction score was attributed to "B2 - Learning at any time of the day (schedule flexibility)", followed by other four items. Item B4 "Availability of other learning content (diagrams, organization of assignments, schedule, etc.), although been situated in "Q2 - Effective" quadrant, is the one who scores lowest satisfaction scores among the other system characteristics of this Dimension (5.31) but has lower importance from user's perspective (4.97). 


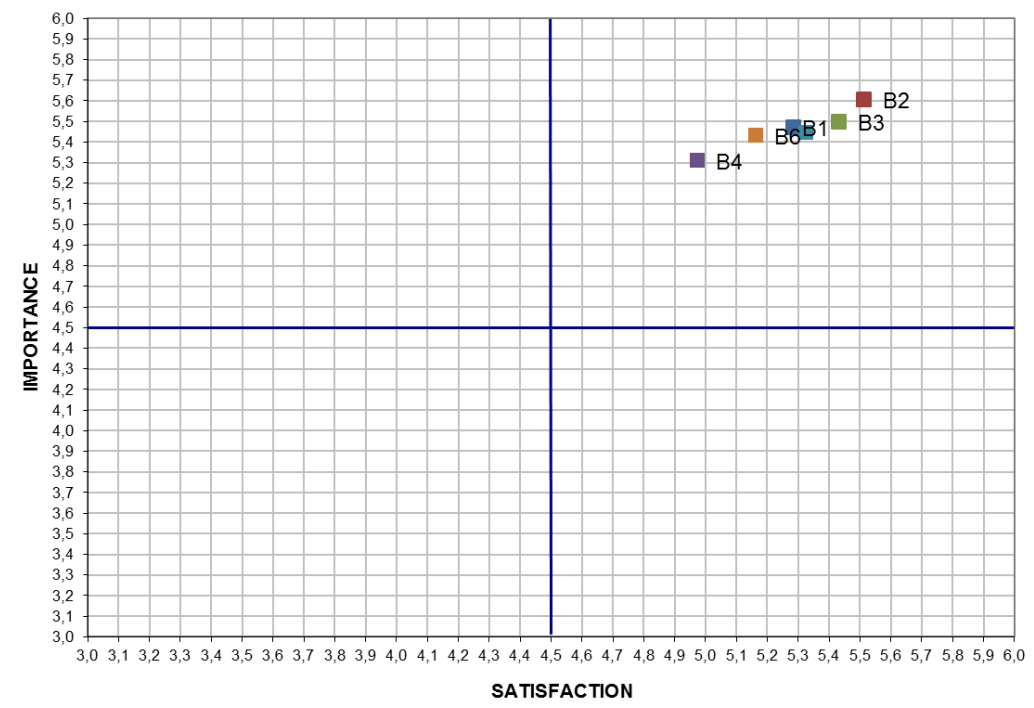

Figure 6. Value-Satisfaction Grid Dimension B - Access and Navigation

\section{LeVIS Index for Dimension B}

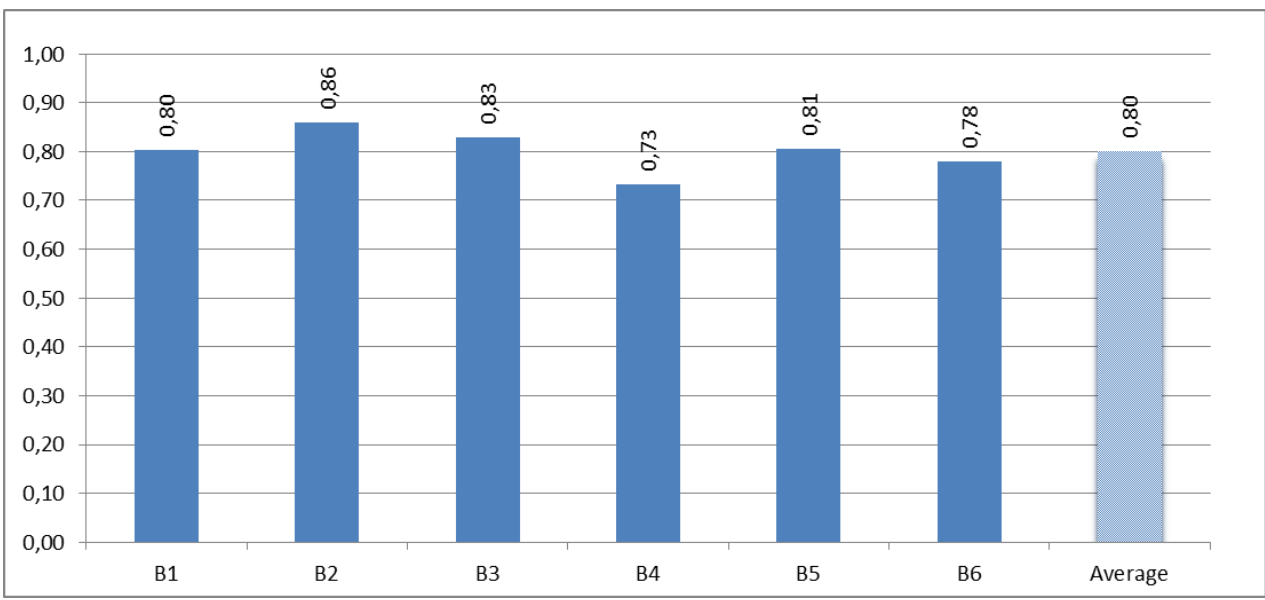

Figure 7. LeVIS Index Dimension $B$ - Access and Navigation

Given the results of LeVIS Index of Dimension B - Access and Navigation (Figure 7), the global score reveals a "high effectiveness" $(\geq 0.75 \&<0.9375)$ having a response score average of 0.80 . More specifically, and according to Figure 7, only item B4 scores below 0.75 (high effectiveness), been categorized as "Good effectiveness".

\section{Dimension C - Perceived Value}

\section{Value-Satisfaction Grid for Dimension C}

The Value-Satisfaction Grid for Dimension C - Perceived Value (Figure 8) illustrates that all five e-learning system characteristics were placed in the quadrant of high satisfaction and high value, i.e., in "Q2 - Effective" quadrant. Students are very satisfied and have high value with characteristics such as comfort with e-learning and technology, Internet and computer skills, ability to travel while taking online courses (for business \& others), self-discipline, as well as time management. Item C3 (self- 
discipline \& time management) although is valued, is viewed by students as having lower satisfaction score among other characteristics of this Dimensions. Students feel that this typology of asynchronous e-learning is demanding in terms of self-discipline and time management and recognize this item as very important.

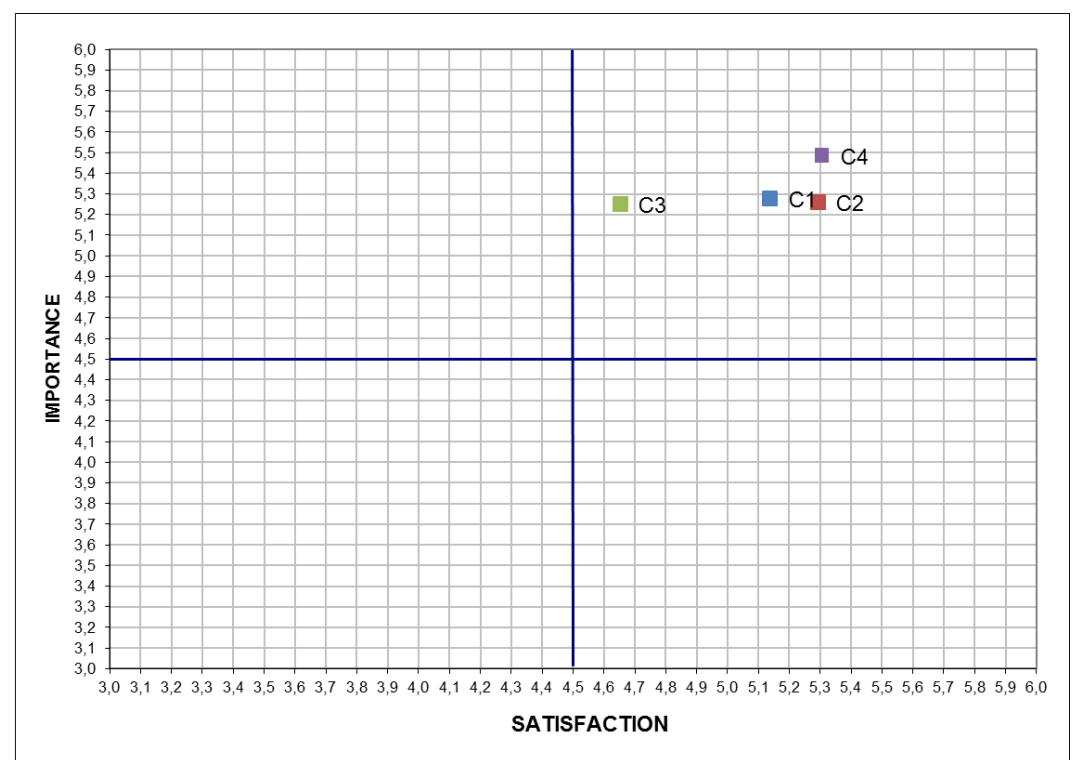

Figure 8. Value-Satisfaction Grid Dimension C - Perceived Value

\section{LeVIS index Dimension C}

Given the results of LeVIS index of Dimension C - Perceived Value, the global score reveals a "high effectiveness" $(\geq 0.75 \&<0.9375)$ having a response score average of 0.76. More specifically, and according to Figure 9, item C3 score 0.68 , is the only item clearly above the average score of the other Dimension items.

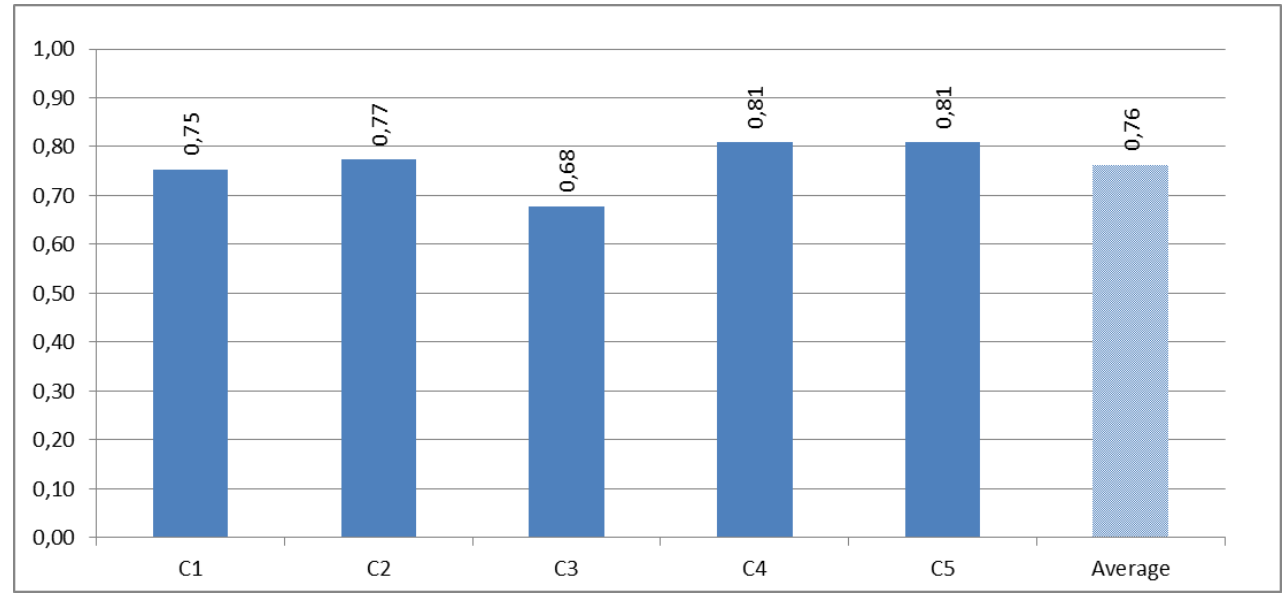

Figure 9. LeVIS Index Dimension C - Perceived Value 


\section{Overall Dimensions A, B, C, and All System Characteristics Overall Value-Satisfaction Grid}

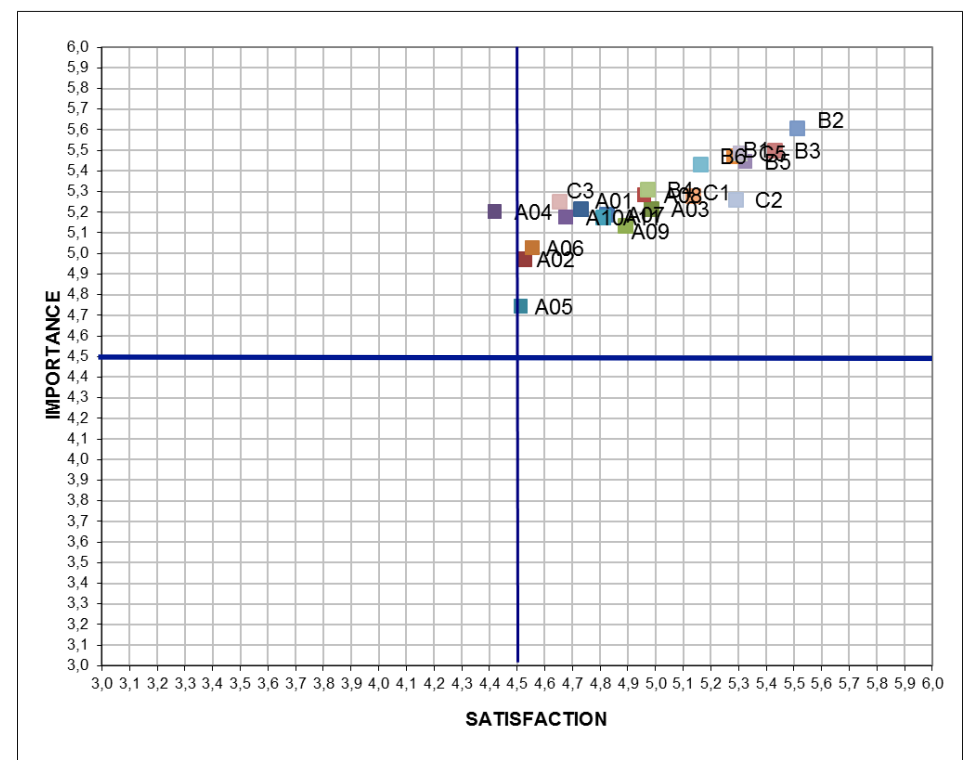

Figure 10. Overall Value-Satisfaction Grid (All Dimensions)

Figure 10 (The Overall Value-Satisfaction Grid (Dimension A, B, \& C - 25 system characteristics) graphically shows that 22 items $(96 \%)$ are placed in the in the quadrant of high satisfaction and high value, i.e., in "Q2 - Effective" quadrant. There is only one item situated in the "Q1- Improvement" quadrant - A4 (Difficulty of subject matter), therefor this should be the priority of quality improvement intervention measures. Also, special attention should be recommended in the analysis of items A5 (Access to other contents/resources (content of courses, organization of assignments, etc. across all course modules)) and A2 (Amount of material in courses) once they are situated very near the "border" of "Q1 - Improvement" quadrant". The main concern in this project is item A4 (Difficulty of subject matter), which denotes high importance score (5.20), and should have a higher satisfaction score. We will discuss some possible causes of the results of item A4 further.

\section{Overall LeVIS Index: Assessing Overall Level of Effectiveness}

Levy (2006) and Levy et al. (2009) proposed the following categorization for LeVIS Index overall scores:

- If LeVIS overall score is $\geq 0.9375$ - Very high effectiveness;

- If LeVIS overall score is $\geq 0.75$ and $<0.9375$ - High effectiveness;

- If LeVIS overall score is $\geq 0.5625$ and $<0.75$ - Good effectiveness;

- If LeVIS overall score is $\geq 0.3750$ and $<0.5625$ - Moderate effectiveness;

- If LeVIS overall score is $\geq 0.1875$ and $<0.3750$ - Low effectiveness and

- If LeVIS overall score is $<0.1875$ - Very low effectiveness.

As can be seen in Figure 11, the results from the Overall LeVIS Index indicate that the overall e-learning system under study reached a global score of $\mathbf{0 . 7 5}$, therefor users' classified as "high effectiveness" $(\geq 0.75)$. Quality improvement measures should be 
developed, especially focusing the Dimension A (mainly A4, A5, \& A2) to promote global score to levels of very high effectiveness.

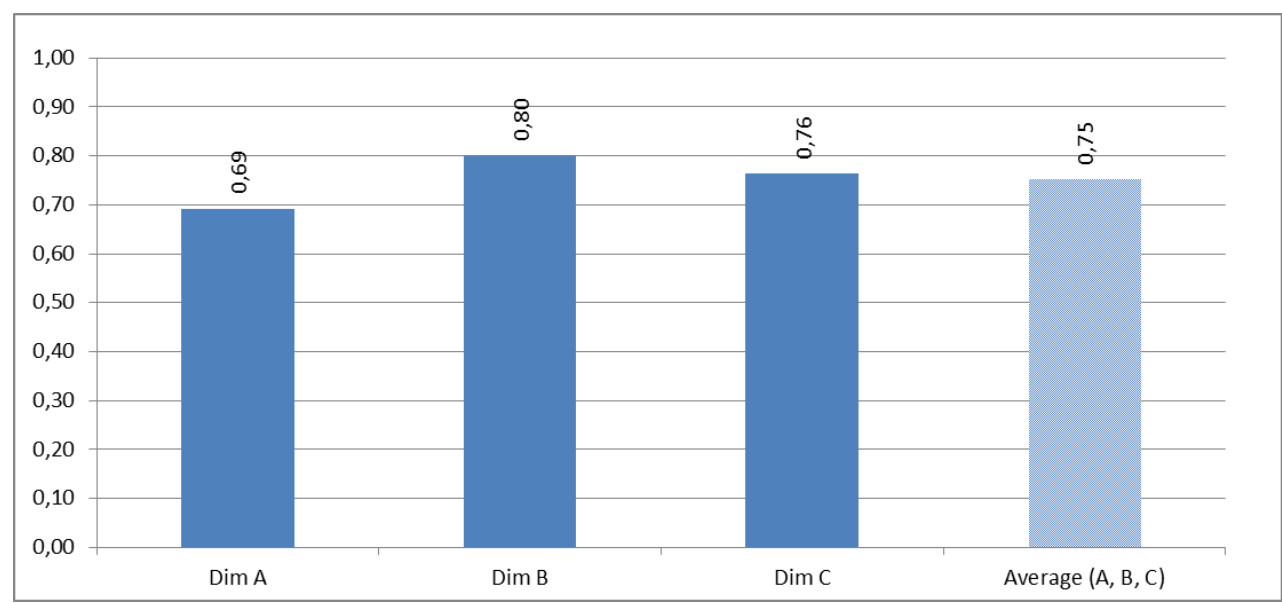

Figure 11. Overall LeVIS Index - Overall Value of Effectiveness

\section{FDC's Perspective}

From the FDC's perspective, the opportunity to apply the IPTEACES e-learning framework in one of the courses of the EMBA was very positive, either by the possibility to improve student's learning or the creation of a new educational methodology. The development and application of the new e-learning course required arrangement, design, implementation, execution, and assessment. This section aims to discuss FDC's perspective in all these phases. Figure 12 shows the steps carried out when implementing the IPTEACES e-learning framework in the EMBA.

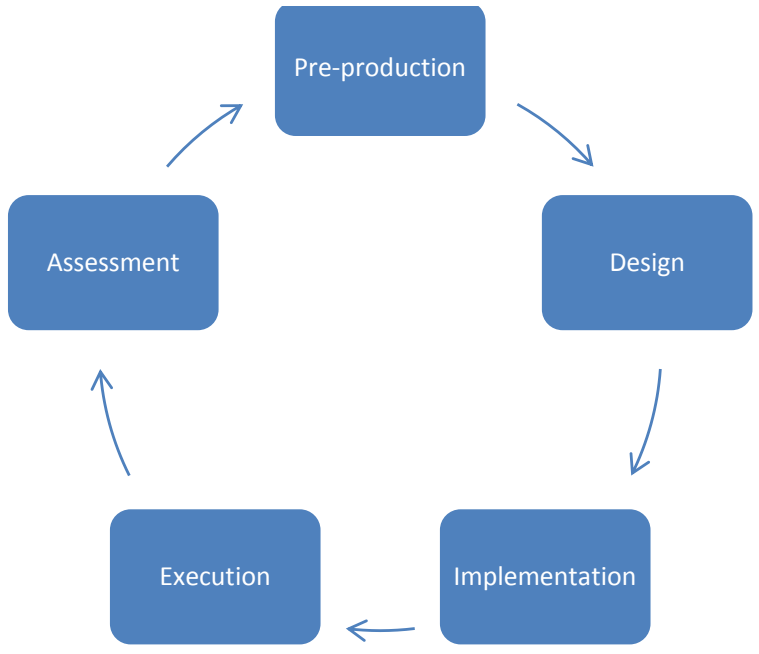

Figure 12. Phases of Development and Application of IPTEACES e-Learning Framework

The new e-learning developed via IPTEACES e-learning framework required 11 months for the completion of all five phases. One of the first steps of the pre- 
production phase was to involve the Brazilian Professor in charge of the face-to-face class that would be converted to a digital learning (e-learning) class using IPTEACES elearning framework. He was challenged to document all the lectures and practices he used with the students in attendance classes. After a cautious analysis of the Professor's written lectures, FDC's team organized the content into units to facilitate the student's understanding. The structure defined five learning digital objects that would be later hosted in a learning management system already adopted by the institution.

In the design phase, the storyboards were developed based on the written material conceived in the arrangement stage following in detail IPTEACES e-learning framework. The Professor's knowledge of the most common student's doubts was very useful to guide the construction of the e-learning units. The language also required careful analysis since the Portuguese from Portugal is not exactly the same as Brazilian. According to the IPTEACES e-learning framework, the storyboards were developed in PowerPoint files and simulated the working dynamics of each unit. The two EMBA elearning Assistant Professors of Finance also revised the PowerPoint files (storyboard). After the approval of the storyboards, corresponding to each unit, the implementation phase involved first to the development of HTML5 files and subsequently in the generation of SCORM packages to be later hosted by the FDC's Learning Management System (LMS).

During the implementation phase, face-to-face session preceded the e-learning session, where the Assistant Professors presented the readings, methodology, and deadlines of the online activities. This presentation was adapted so that students could understand they would first go through a self-instructional class on Basic Finance and then proceed to the actual Finance distance-learning activities. The FDC team supported both elearning Assistant Professors of Finance in this process and aligned everything with the Professor in charge of the face-to-face Finance class.

In the execution phase of Basic Finance class, students followed a specific calendar, when they took lessons and worked in self-instructional activities. The fixation exercises were designed for students to take care of their own educational process and learn from their wrong answers, while appreciate the correct ones. Minor technical adjustments and improvements were made after the first cohort took the course and before it was made available to the second and third cohorts. After the end of the course, every student was invited to answer a survey to assess student's satisfaction and value perception, as well as other aspects such accessibility, ease to use, and most importantly, whether this e-learning contributed to their knowledge assimilation. The results confirmed that the students considered valid the use of this educational methodology and agreed it was useful for the achievement of the expected learning outcomes. As a conclusion, the global assessment showed that the e-learning based in IPTEACES e-learning framework should be used as a powerful tool for student's development. The whole experience was motivating and important for both the professor and the students.

\section{Discussions, Theoretical, and Practical Significance}

This study, part of the three higher education experiments of the application of IPTEACES e-learning framework in leading business schools, namely, Portugal (Pena 
et al., 2015), Australia (Tomayess et al., in Press), and Brazil, aimed to investigate if IPTEACES e-learning framework can be pedagogically effective in the context of higher education and in different geographies. This study reports the Brazilian trail of the application of the IPTEACES e-learning framework in higher education, more specifically in FDC's EMBA program.

Results shows that the use of this e-learning framework in FDC's EMBA program has accomplished a Overall LeVIS Index score of 0.75 , indicating that users' classified it as "high effectiveness" $(\geq 0.75)$. These results provide a strong validation for the use of IPTEACES e-learning framework in different higher education programs, in different geographies. As stated previously, the rapid growth of online academic programs in higher education has prompted institutions to develop processes and implement strategies to ensure the quality of their online offerings (Britto et al., 2014). E-learning's quality has become an issue of increasing importance in both researchers' and practitioners' communities. In this sense, and from a quality assurance perspective, quality improvement measures should be developed, especially focusing the Dimension A (mainly A4, A5, \& A2) to promote global score to levels of very high effectiveness.

The Value-Satisfaction Grid on Dimension A - Course Contents (presented on Section 4), highlighted that item A4 (Difficulty of subject matter) was situated in the "Q1Improvement" quadrant. This item (A4) denotes high importance score from students (5.20), but the satisfaction score is lower ( 4.41 - between satisfied \& highly satisfied). We believe these scores are a result of the fact that the discipline reported in this study, i.e. Finance, one of the most difficult disciplines in the EMBA program, as one can note in the following comment made by a student in the survey:

"In subjects on which I have a better ability, the online course is assertive and relevant. However, in the case of Finance, with which I am not very familiar, it was very difficult for me to learn, even though I did exchange ideas in the platform and with classmates. I have no doubts that should this class be delivered face-to-face; my understanding would have been extremely better".

Another point that comes out of this comment is that students might also have taken into consideration the e-learning session of Finance when answering the survey, not only the Basic Finance online content. The online class is followed by the e-learning activities during the same intermission, i.e. between the second and third face-to-face modules, so students might have evaluated these two phases as only one. The following comment supports this proposition, since students use a workbook in the e-learning activities which is not part of the online class on Basic Finance:

"I found the workbook very hard to understand. Without face-to-face class or interaction, the contents are too complicated to understand".

Besides the survey results, it should also be highlighted that the evaluation made by students on the Finance course that is delivered after the e-learning activities and the followed the same usual pattern as it did when the Basic Finance course was delivered face-to-face. In other words, the fact that students had the Basic Finance course online did not change anything on their learning outcomes in Finance face-to-face course. Student's comments were positive regarding the face-to-face and e-earning activities, reflecting that the change produced no detriment to the subsequent classes. This 
perception was shared by both Assistant Professors and by the professor in charge of the Finance course. Therefore, it is safe to imply that the online course on Basic Finance achieved its goal of getting students ready for the Finance course.

\section{Limitations and Conclusion}

IPTEACES e-learning framework was originally conceived and designed as an instructional design framework for online corporate learning that could enable an integrated implementation of an appropriate learning strategy for different learners. The rationale for this study was to examine whether the use of IPTEACES e-learning framework, applied in the context of FDC's EMBA would (i) promote students' learning; (ii) assess its effectiveness and determine specific quality improvement measures' and (iii) how IPTEACES e-learning framework enhances organizational learning approach/products. This research is part of a wider investigation that has the objective of analyzing the implementation of IPTEACES e-learning framework in PostGraduation Courses in Brazil, Portugal, and Australia.

The FDC experience was limited to Basic Finance course and future work should explore more disciplines (e-learning activities) as well as incorporating results from other implementations. Nevertheless, results are highly motivating, showing that the application of the IPTEACES e-learning framework to this new learning modality of the course has reached high effectiveness $(0.75)$. The Overall Value-Satisfaction Grid (Dimension A, B, \& C) showed that $96 \%$ of the items are placed in the in the quadrant of high satisfaction and high value, i.e., in "Q2 - Effective" quadrant. There is only one item situated in the "Q1- Improvement" quadrant - A4 (Difficulty of subject matter), therefor, this should be the priority of quality improvement intervention measures. Also, special attention should be recommended in the analysis of items A5 (Access to other contents/resources (content of courses, organization of assignments, etc. across all course modules) and A2 (Amount of material in courses) once they are situated very near the "border" of "Q1 - Improvement" quadrant". As stated previously, based on informal feedback from students, we believe these scores are a result of the fact that this discipline is Finance, one of the most difficult disciplines of the EMBA Program.

\section{References}

Ball, C. J. E. (1985). What the hell is quality? In Ball, C. J. E., Dorma, U. \& Society for Research (Ed.) Fitness for purpose - essays in higher education. SRHE \& NFER-Nelson, Guildford, Surrey, pp. 96-102.

Bersin and Associates (2012). Learning leaders is now the Bersin and Associates whatworks awards. Retrieved from http://bersin.com/wwawards/

Brandon Hall Group (2012). Winners of the 2012 Brandon hall excellence in learning awards. Retrieved from: http://www.brandonhall.com/awards/excellence-inlearning/winners-of-the-2012.html

Britto, M., Ford, C., \& Wise, J. (2014). Three institutions, three approaches, one goal: addressing quality assurance in online learning. Journal of Asynchronous Learning Networks, 17(4), 11-23. 
Doll, W. J., \& Torkzadeh, G., (1991). The measurement of end-user computing satisfaction: Theoretical and methodological issues. MIS Quarterly, 15(1), 5-9.

Dondi, C., Moretti, M., \& F. Nascimbeni, (2006). Quality of e-learning: Negotiating a strategy, implementing a policy. In Ehlers, U. D., \& Pawlowski, J. M. (Eds.) Handbook on Quality and Standardisation in E-learning (pp. 31-50). New York, NY: Springer.

Ehlers, U. D., \& Hilera, J. R. (2012). Special issue on quality in e-learning. Journal of Computer Assisted Learning, 28(1), 1-3.

Ehlers, U. D., Camilleri, A. F., \& Pawlowski, J. (2014). State of the art review of quality issues related to open educational resources (OER). Luxembourg City, Luxembourg: European Commission. Retrieved from: https://www.pedocs.de/ volltexte/2014/9101/pdf/European_Commission_2014_OER.pdf

Gagne, R. M., Briggs, L., \& Wager, W. W. (1992). Principles of instructional design. Fort Worth, TX: Harcourt Brace Jovanovich College Publishers.

Grönroos, C. (2007). Service management and marketing: Customer management in service competition ( $3^{\text {rd }}$ ed.). New York, NY: John Wiley \& Sons Ltd.

Juran, J. M. (1992). Juran on quality by design: The new steps for planning quality into goods and services. New York, NY: Free Press.

Keller, J. M. (2008). First principles of motivation to learn and $\mathrm{e}^{3}$-learning. Distance Education 29(2), 175-185.

Keller, J. M. (2010). Motivational design for learning and performance: The ARCS model approach. New York, NY: Springer.

International Organizational for Standardization (2000). ISO 9001:2000 - Quality management systems. Genève, Switzerland: International Organization for Standardization.

Levy, Y. (2006). Assessing the value of e-learning systems. Hershey, PA: Information Science Publishing.

Levy, Y., Murphy, K. E., \& Zanakis, S. H. (2009). A value-satisfaction taxonomy of IS effectiveness (VSTISE): A case study of user satisfaction with IS and userperceived value of IS. International Journal of Information Systems in the Service Sector, 1(1), 93-118.

Levy, Y., \& Murphy, K. (2002). Toward a value framework for online learning system. In Proceedings for the Hawaii International Conference on System Sciences, Big Island, Hawaii, pp. 1-9.

Merriënboer, J. J. G., \& Kirschner, P. A. (2007). Ten steps to complex learning. Mahwah, NJ: Lawrence Erlbaum Associates.

Merrill, M. D. (2002). First principles of instruction. Educational Technology Research and Development, 50(3), 43-59. 
Merrill, M. D. (2007). First Principles of Instruction: A Synthesis. In R. A. Reiser \& J. V. Dempsey (Eds.), Trends and Issues in Instructional Design and Technology. Columbus: Ohio: Merrill Prentice Hall.

Pena, N. (2016). The learning officer decision matrix - A structured equation modeling approach for the management of asynchronous e-learning projects. Online Journal of Applied Knowledge Management, 4(1), 133-149.

Pena, N., Gonçalves, D., \& Lopes, A. (2015). Estudo de caso do curso Fundamentos de Inferência Estatística, in Guia Prático do e-learning - Casos práticos nas organizações, Ed. Vida Económica, Porto, Portugal.

Pena, N., \& Isaias, P. (2011). The IPTEACES e-learning framework - success indicators, the impact on student social demographic characteristics and the assessment of effectiveness. In Towards Learning and Instruction in Web 3.0. Advances in Cognitive and Educational Psychology. New York, NY: Springer.

Pena, N., \& Isaias, P. (2013). Assessing the effectiveness of an e-learning framework: The Portuguese insurance academy case. Journal of Cases on Information Technology, 15(1), 1-18.

Tomayess, I, Pena, N., \& Isaias, P. (in Press). Assessing the effectiveness of IPTEACES e-learning framework in higher education: An Australian's perspective. In Big data analytical: Social network approach. Boca Raton, FL: CRC Press.

Webster, J., \& Hackley, P. (1997).Teaching effectiveness in technology-mediated distance learning. Academy of Management Journal, 40(6), 1282-1309.

\section{Authors' Biographies}

Nuno Pena is a Senior Learning Director, Assistant Professor and Integrated Researcher at ADVANCE Research Center of ISEG - Lisbon School of Economics and Management (University of Lisbon); Post-Doctoral Fellow in Lifelong Learning, PostDoctorate in Management Information Systems, Doctorate (Ph.D.) in Information Management, MEd Digital Education, PGCE in Education, and BPhil in Philosophy.

Paula Simões is Associate Dean for Faculty and Research and Professor at Fundação Dom Cabral; Doctorate (PhD) in Organizational Change Management, by Newcastle University - UK; Msc in Marketing and Strategic Management and Bachelor in Business Administration, by the Federal University of Minas Gerais - UFMG.

Lília Mascarenhas is an Educational Technology Specialist in Education and Innovation Department at Fundação Dom Cabral; Master's in computer science and Graduated in Physics at Federal University of Minas Gerais, Regional Coordinator at ABED - Digital Educational Brazilian Association.

Flávia Alvim is an Affiliate Professor at Fundação Dom Cabral - FDC and works on projects and researches in the fields of Sustainability, International Business, and Strategy; Master's Degree (MsC) in Development Management from London School of 
Special Issue on Knowledge Management: Research, Organization, and Applied Innovation

Economics and Political Science - LSE, Graduate Certificate in Social Management from Fundação João Pinheiro, Bachelors' Degrees in International Relations from PUC Minas, and in Business Administration from Universidade Federal de Minas Gerais UFMG. 


\section{APPENDIX A}

\section{COURSE CONTENTS DIMENSION}

\begin{tabular}{|l|l|}
\hline A1 & Quality content of courses \\
\hline A2 & Amount of material in courses \\
\hline A3 & Interesting subject matter \\
\hline A4 & Difficulty of subject matter \\
\hline A5 & Availability of other content (syllabus, objectives, assignments, schedule) \\
\hline A6 & Enjoyment from the courses/lessons \\
\hline A7 & Ease-of-use (with course content, navigation, interface, etc.) \\
\hline A8 & Gathering information quickly \\
\hline A9 & $\begin{array}{l}\text { Organization of courses (content of courses, organization of assignments, etc. across all } \\
\text { course modules) }\end{array}$ \\
\hline A10 & Learning a lot in these classes \\
\hline ACCESS AND NAVIGATION DIMENSION \\
\hline B1 & Access to courses from anywhere in the world (via the Internet) \\
\hline B2 & Learning at anytime of the day (schedule flexibility) \\
\hline B3 & Submit assignments from anywhere (via the Internet) \\
\hline B4 & Different system tools (chat, bulletin-board or discussion forums, etc.) \\
\hline B5 & Access of all courses from one area (My LMS) \\
\hline B6 & Review course materials \\
\hline PERCEIVED VALUE DIMENSION \\
\hline C1 & Your comfort with online learning and technology \\
\hline C2 & Your Internet and computer skills \\
\hline C3 & Self-discipline and time management \\
\hline C4 & Reduced travel cost/time (to and from campus) \\
\hline C5 & Ability to travel while taking online courses (for business or other) \\
\hline & \\
\hline
\end{tabular}

